\title{
Alternative Public Health Interventions to Prevent Neonatal Deaths in Developing Countries: A Comparative Study
}

\author{
Shahid Umar \\ Department of Public Administration and Policy, Rockefeller College of Public Affairs and Policy, University at Albany, State \\ University of New York, New York 11235, USA
}

\begin{abstract}
A number of evaluations of health education interventions in developing countries for the reduction of neonatal mortality have been reported. These interventions can be divided into two categories: those which include medical professionals and those without medical professionals. No systematic review has yet been performed that compares these two types of interventions. This study is an attempt to determine whether the inclusion of medical professionals in health education interventions more greatly decreases neonatal mortality in developing countries. Databases were searched for impact evaluation studies which: 1) had both experimental and control groups, 2) conducted both pre-tests and post-tests, 3) identified the intervention as a health education package, 4) were published in peer reviewed journals, 5) used neonatal mortality as an outcome measure, and 6) were undertaken in developing countries. A total 14 studies were found that fit these criteria - eight of these studies included medical professionals in the intervention, and six studies were without medical professionals. To calculate the net effect of each intervention, both the difference-in-difference method and the use of log odds ratios were tested. Interventions involving medical professionals had significantly lower neonatal mortality rates than those without medical professionals. Interventions meant to decrease neonatal mortality in developing countries are recommended to involve medical professionals.
\end{abstract}

Key words: Neonatal mortality, health education interventions, developing countries, medical professionals.

\section{Introduction}

Every year, nearly three million infants die worldwide within the first month following their birth. There are a similar number of still births in the world [1]. Ninety-eight percent of these deaths occur in developing countries [2]. A majority of these deaths are preventable through low-cost and effective interventions [3]. A variety of health education interventions intended to reduce neonatal mortality have been implemented in developing countries, and a number of evaluations of these interventions have been reported.

Health education interventions intended to reduce neonatal mortality can be divided into two categories: those which include medical professionals and those

Corresponding author: Shahid Umar, Ph.D., research fields: public health, public management, monitoring and evaluation. without medical professional involvement. No systematic review has yet been performed that compares these two types of intervention. This study is an attempt to determine whether the inclusion of medical professionals in health education interventions more greatly decreases neonatal mortality in developing countries.

\section{Methods}

Searches were conducted of various electronic databases such as PubMed, Popline, Science Direct, JSTOR, EBSCO: Academic Search Complete, and Google Scholar to identify studies which: 1) had both experimental and control groups, 2) conducted both pre-tests and post-tests, 3 ) identified the intervention as a health education package, 4) were published in peer-reviewed journals, 5) had neonatal mortality (death of a live born infant within 28 completed days of 


\section{Alternative Public Health Interventions to Prevent Neonatal Deaths in Developing Countries: A Comparative Study}

birth) as an outcome measure, and 6) were undertaken in developing countries. Some of the key terms used to search the databases were (among others): "randomized controlled trials", "health education", "developing countr*", "neonatal mortality", "birth outcome", and "experimental stud*". Similar terms were used for searches of the electronic sources of the following academic journals: The Lancet, Bulletin of the World Health Organization, British Medical Journal, Health Education Research, and Patient Education and Counseling. This search followed the Preferred Reporting Items for Systematic Review and Meta-Analysis (PRISMA) guidelines. The reference section of each article identified was yet another source to locate additional articles for this review.

In total, 15 impact evaluation studies were found which met the criteria for inclusion in this review. Two studies $[4,5]$ reported results of the same period of the same trials and one of those [5] was excluded from the review. Six of the remaining 14 experimental studies were found to be without involvement of medical professionals in the intervention (Table 1) [6-11]; eight experimental studies included medical professionals in the intervention (Table 2) [4, 12-18].

In accordance with the Problem/Population, Intervention, Comparison and Outcome (PICO) framework the 14 impact evaluation studies included in this review are those in which 1) the target population was pregnant women and neonates in developing countries, 2) the intervention was health education including community-based interventions, participatory interventions, home-based interventions and population-based interventions, 3 ) both pre-test (baseline) and post-test data for both treatment and control groups were made available, and 4) a standard outcome measure of 28-day neonatal mortality was reported.

\section{Results}

Results of these 14 studies are summarized in Table 3. The baseline and post-test neonatal mortality rates per 1,000 live births of both control and experimental groups for each study are shown. The difference between baseline and post-test of each group also is reported, where difference indicates the change in the

Table 1 Summary of studies without medical professionals.

\begin{tabular}{|c|c|c|c|c|}
\hline $\begin{array}{l}\text { Sr. } \\
\text { No. }\end{array}$ & Authors (year) & Location & $\begin{array}{l}\text { Years of } \\
\text { intervention }\end{array}$ & Intervention \\
\hline & $\begin{array}{l}\text { Azad et al. } \\
(2010)[6]\end{array}$ & Bangl-adesh & $2005-2006$ & $\begin{array}{l}\text { The women who had given birth to a child during study period were taught in } \\
\text { groups to deal with maternal and neonatal health issues. Group facilitators in } \\
\text { communities were responsible for visiting households to join educational } \\
\text { groups and community mobilization. }\end{array}$ \\
\hline & $\begin{array}{l}\text { Tripathy et al. } \\
(2010)[7]\end{array}$ & India & $2005-2008$ & $\begin{array}{l}\text { The women in experimental group received a community-based health } \\
\text { educational intervention for addressing maternal and newborn health problems. } \\
\text { The eligible women were taught about clean delivery practices and } \\
\text { care-seeking behavior in groups formed at community level. }\end{array}$ \\
\hline & $\begin{array}{l}\text { Manandhar et al. } \\
(2004)[8]\end{array}$ & Nepal & $2001-2003$ & $\begin{array}{l}\text { The women in experimental group received a health educational treatment } \\
\text { through community-based approach. Selected facilitators in each cluster } \\
\text { educated women about perinatal problems and strategies to address these } \\
\text { problems. }\end{array}$ \\
\hline & $\begin{array}{l}\text { Greenwood et } \\
\text { al. (1990) [9] }\end{array}$ & Gambia & $1982-1987$ & $\begin{array}{l}\text { Village health workers (VHWs) and traditional birth attendants were trained to } \\
\text { recognize and treat common conditions among pregnant women. They also } \\
\text { educated women about these issues, encourage immunization and give } \\
\text { nutritional advice. }\end{array}$ \\
\hline & $\begin{array}{l}\text { Baqui et al. } \\
(2008) \text { [10] }\end{array}$ & Bangl-adesh & $2003-2005$ & $\begin{array}{l}\text { In the home-care experimental group the pregnant women were educated about } \\
\text { newborn care preparedness and neonatal health issues by female community } \\
\text { health workers in their homes. In the community-care experimental group the } \\
\text { pregnant women were educated in group sessions. }\end{array}$ \\
\hline & $\begin{array}{l}\text { Kirkwood et al. } \\
(2013)[11]\end{array}$ & Ghana & 2008-2009 & $\begin{array}{l}\text { Community-Based Surveillance Volunteers (CBSVs) were trained to make } \\
\text { home visits of pregnant women and teach them about maternal health issues } \\
\text { and newborn-care practices. CBSVs made total five visits of pregnant women, } \\
\text { two during pregnancy and three in the first week of delivery. }\end{array}$ \\
\hline
\end{tabular}


Table 2 Summary of studies involving medical professionals.

\begin{tabular}{|c|c|c|c|c|}
\hline Sr. No. & Authors (year) & Location & $\begin{array}{l}\text { Years of } \\
\text { Intervention }\end{array}$ & Intervention \\
\hline & $\begin{array}{l}\text { Bhutta et al. } \\
(2008)[12]\end{array}$ & Pakistan & 2003-2005 & $\begin{array}{l}\text { The women in the experimental group were educated by trained Lady health } \\
\text { workers (LHWs) and birth attendants (Dais) in group sessions about essential } \\
\text { maternal and newborn care. The treatment was delivered with the help of } \\
\text { voluntary community health committees. }\end{array}$ \\
\hline & $\begin{array}{l}\text { Kumar et al. } \\
(2008)[4]\end{array}$ & India & 2004-2005 & $\begin{array}{l}\text { One experimental group was given preventive essential newborn care through } \\
\text { behavioral change management approach. The other experimental group } \\
\text { received essential newborn care in addition to The room spot with the help of } \\
\text { medical professionals. }\end{array}$ \\
\hline & $\begin{array}{l}\text { Bang et al. } \\
(1999)[13]\end{array}$ & India & 1995-1998 & $\begin{array}{l}\text { In this home-based care intervention, village health workers and traditional } \\
\text { birth attendants were trained to deal with neonatal and maternal care problems. } \\
\text { Doctors visited fortnightly to oversee the ongoing treatments. }\end{array}$ \\
\hline & $\begin{array}{l}\text { Midhet and } \\
\text { Becker }(2010) \\
{[14]}\end{array}$ & Pakistan & $2000-2002$ & $\begin{array}{l}\text { In one experimental group, the women were taught about safe motherhood by } \\
\text { the trained birth attendants. In the other experimental group, husbands were } \\
\text { also educated about safe motherhood and family planning. The birth attendants } \\
\text { were also trained to recognize obstetric and newborn complication. Doctors at } \\
\text { district level were made available in case of newborn complication. }\end{array}$ \\
\hline & $\begin{array}{l}\text { Bang et al. } \\
(2005)[15]\end{array}$ & India & $1996-2003$ & $\begin{array}{l}\text { Village health workers and lower-level medical professionals were trained to } \\
\text { deal with neonatal and maternal care problems. In addition, the women in the } \\
\text { experimental group were educated by trained village health workers with the } \\
\text { help of traditional birth attendants about neonatal care issues. Medical } \\
\text { professionals oversaw the treatment. }\end{array}$ \\
\hline & $\begin{array}{l}\text { Bhutta et al. } \\
(2011) \text { [16] }\end{array}$ & Pakistan & 2006-2008 & $\begin{array}{l}\text { The trained LHWs with the help of community health committees and } \\
\text { traditional birth attendants educated women in experimental group about } \\
\text { newborn care and issues related to maternal health. This community-based } \\
\text { treatment was delivered in group sessions. }\end{array}$ \\
\hline & $\begin{array}{l}\text { Persson et al. } \\
(2013)[17]\end{array}$ & Vietnam & 2008-2011 & $\begin{array}{l}\text { Local stakeholders such as community members, local health care staff and } \\
\text { community mobilizers were involved to monitor a health education treatment. } \\
\text { Health care staff and key persons, called Maternal and Newborn Health Group } \\
\text { (MNHG), met with pregnant mothers each month to discuss and solve health } \\
\text { problems in groups. }\end{array}$ \\
\hline & $\begin{array}{l}\text { Jokhio et al. } \\
(2005)[18]\end{array}$ & Pakistan & 1998 & $\begin{array}{l}\text { The eligible women in the experimental group received maternal and antenatal } \\
\text { care from trained traditional birth attendants. Traditional birth attendants } \\
\text { visited homes of pregnant women at least three times during pregnancy. LHWs } \\
\text { were also trained to support birth attendants. }\end{array}$ \\
\hline
\end{tabular}

LHWs in Pakistan are considered medical professionals in this paper for the following reasons: 1) they received formal training for 15 months, 2) they are employees of a Ministry of Health, and 3) they are paid for their work, unlike VHWs, Community Health Workers (CHWs) or CBSVs in other countries.

neonatal mortality rate during the period of intervention. A positive difference indicates an increase in the neonatal mortality rate during the intervention period; a negative difference indicates a reduction. Odds ratios and $\log$ odds ratios also are shown in Table 3, as an alternative calculation of the impact of an intervention. Odds ratios are obtained by dividing a post-test mortality rate by the respective baseline rate for the same group. Odds ratios equal to 1.00 or greater indicate no change or worsening of infant mortality. Odds ratios less than 1.00 indicate a reduction in rate during the intervention period. A log odds ratio is the natural $\log$ of an odds ratio that expresses the rate change as an equal interval scale.

For each of the 14 studies, a difference-in-difference (DID) statistic was calculated by subtracting the baseline $\left(\mathrm{O}_{2}\right)$ and post-test $\left(\mathrm{O}_{4}\right)$ difference for the control condition from the baseline $\left(\mathrm{O}_{1}\right)$ and post-test $\left(\mathrm{O}_{3}\right)$ difference for the experimental condition, that is, $\left(\mathrm{O}_{3}-\mathrm{O}_{1}\right)-\left(\mathrm{O}_{4}-\mathrm{O}_{2}\right)$. The more negative the DID statistic for each study, the greater was the reduction in neonatal mortality when medical professionals were involved in the health education intervention. A similar statistic was computed as the difference in log odds ratios for 


\section{Alternative Public Health Interventions to Prevent Neonatal Deaths in Developing Countries: A Comparative Study}

experimental and control conditions in each of the 14 studies and interpreted in an identical manner.

The arithmetic mean and standard deviation of DID statistics for the eight studies in which medical professionals were involved are shown in Table 4; the arithmetic mean and standard deviation of DID statistics for the six studies without medical professional involvement also are shown. Similarly, arithmetic means and standard deviations for the differences in log odds ratios are displayed as a second row of statistics in Table 4. DID statistics and differences in log odds ratios were highly correlated across studies $(\mathrm{r}=0.92)$, but these alternative calculations did not entirely converge.

Table 3 Baseline and post-test mortality rates with their differences, odds ratios and log odds ratios for the 14 studies.

\begin{tabular}{|c|c|c|c|c|c|c|}
\hline Study & Condition & Baseline & Post-test & Difference & Odds Ratios & Log Odds Ratios \\
\hline \multicolumn{7}{|c|}{ Studies without involvement of medical professionals in the treatment } \\
\hline \multirow{2}{*}{ Azad et al. [6] } & Control & 26.9 & 34.4 & +7.5 & 1.28 & 0.25 \\
\hline & Experimental & 21.6 & 35.2 & +13.6 & 1.63 & 0.49 \\
\hline \multirow{2}{*}{ Tripathy et al. [7] } & Control & 53.6 & 64.3 & +10.7 & 1.20 & 0.18 \\
\hline & Experimental & 61.8 & 36.3 & -25.5 & 0.59 & -0.53 \\
\hline \multirow{2}{*}{ Manandhar et al. [8] } & Control & 25.1 & 36.9 & +11.8 & 1.47 & 0.39 \\
\hline & Experimental & 25.4 & 26.2 & +0.8 & 1.03 & 0.03 \\
\hline \multirow{2}{*}{ Greenwood et al. [9] } & Control & 71.4 & 68.6 & -2.8 & 0.96 & -0.04 \\
\hline & Experimental & 63.2 & 49.2 & -14.0 & 0.78 & -0.25 \\
\hline \multirow{3}{*}{ Baqui et al. [10] } & Control & 48.0 & 43.1 & -4.9 & 0.90 & -0.11 \\
\hline & Experimental $1^{\mathrm{a}}$ & 46.9 & 31.2 & -15.7 & 0.67 & -0.41 \\
\hline & Experimental $2^{\mathrm{b}}$ & 46.7 & 43.5 & -3.2 & 0.93 & -0.07 \\
\hline \multirow{2}{*}{ Kirkwood et al. [11] } & Control & 32.7 & 32.1 & -0.6 & 0.98 & -0.02 \\
\hline & Experimental & 32.3 & 29.5 & -2.8 & 0.91 & -0.09 \\
\hline \multicolumn{7}{|c|}{ Studies with medical professionals involved in the treatment } \\
\hline \multirow{2}{*}{ Bhutta et al. [12] } & Control & 52.2 & 59.8 & +7.6 & 1.15 & 0.14 \\
\hline & Experimental & 57.3 & 41.3 & -16.0 & 0.72 & -0.33 \\
\hline \multirow{3}{*}{ Kumar et al. [4] } & Control & 54.2 & 84.2 & +30.0 & 1.55 & 0.44 \\
\hline & Experimental $1^{\mathrm{c}}$ & 58.9 & 43.2 & -15.7 & 0.73 & -0.31 \\
\hline & Experimental $2^{\mathrm{d}}$ & 64.1 & 41.0 & -23.1 & 0.64 & -0.45 \\
\hline \multirow{2}{*}{ Bang et al. [13] } & Control & 57.7 & 59.6 & +1.9 & 1.03 & 0.03 \\
\hline & Experimental & 62.0 & 25.5 & -36.5 & 0.41 & -0.89 \\
\hline \multirow{3}{*}{ Midhet and Becker [14] } & Control & 42.1 & 48.0 & +5.9 & 1.14 & 0.13 \\
\hline & Experimental $1^{\mathrm{e}}$ & 42.1 & 32.4 & -9.7 & 0.77 & -0.26 \\
\hline & Experimental $2^{\mathrm{f}}$ & 42.1 & 30.5 & -11.6 & 0.72 & -0.32 \\
\hline \multirow[t]{2}{*}{ Bang et al. [15] } & Control & 58.0 & 64.0 & +6.0 & 1.10 & 0.10 \\
\hline & Experimental & 62.0 & 25.0 & -37.0 & 0.40 & -0.91 \\
\hline \multirow[t]{2}{*}{ Bhutta et al. [16] } & Control & 51.3 & 49.1 & -2.2 & 0.96 & -0.04 \\
\hline & Experimental & 48.0 & 43.0 & -5.0 & 0.90 & -0.11 \\
\hline \multirow{2}{*}{ Persson et al. [17] } & Control & 23.2 & 21.1 & -2.1 & 0.91 & -0.09 \\
\hline & Experimental & 24.8 & 11.6 & -13.2 & 0.47 & -0.76 \\
\hline \multirow{2}{*}{ Jokhio et al. [18] } & Control & 43.3 & 53.0 & +9.7 & 1.22 & 0.20 \\
\hline & Experimental & 43.3 & 37.0 & -6.3 & 0.85 & -0.16 \\
\hline \multicolumn{7}{|l|}{ (a) Home care arm. } \\
\hline \multicolumn{7}{|l|}{ (b) Community care arm. } \\
\hline \multicolumn{7}{|c|}{ (c) Essential newborn care + ThermoSpot arm. } \\
\hline \multicolumn{7}{|c|}{ (d) Essential newborn care arm. } \\
\hline \multicolumn{7}{|c|}{ (e) In this arm the treatment was directed to women only. } \\
\hline
\end{tabular}


Table 4 Descriptive and $\boldsymbol{t}$-statistics for Difference-in-difference and difference in log odds ratios.

\begin{tabular}{|c|c|c|c|c|c|}
\hline & \multicolumn{2}{|c|}{ Involvement of Medical Professional } & \multicolumn{3}{|c|}{$\begin{array}{c}\text { No Involvement of Medical } \\
\text { Professionals }\end{array}$} \\
\hline & \multicolumn{2}{|c|}{$(\mathrm{n}=8)$} & \multicolumn{3}{|c|}{$(n=6)$} \\
\hline & Arithmatic Mean & Standard Deviation & Arithmatic Mean & Standard Deviation & $t$-statistic \\
\hline Difference-in-difference & -26.70 & 16.99 & -9.09 & 13.79 & $-2.26^{*}$ \\
\hline Difference in log odds rati & $0.60 \quad 0.30$ & & -0.19 & 0.30 & $-2.70^{*}$ \\
\hline
\end{tabular}
$* P<0.05$.

To test the research hypothesis that the involvement of medical professionals would reduce neonatal mortality rates following health education interventions in developing countries, both the risks of Type I and Type II errors were set as $P<0.05$. Due to the small number of studies available, the effect size was necessarily large, that is, approximately two standard deviations in magnitude ( $\mathrm{D}=2.0)$. The $t$-tests for both DID statistics $(t=-2.26)$ and differences in log odds ratios $(t=-2.70)$ both were significant and supported the research hypothesis. Using a basis of the 14 studies included here, the joint standard deviation parameter for neonatal mortality rates would be approximately 15 neonatal deaths per 1,000 live births across experimental and control settings. Therefore, with an effect size estimated at 2.0, the resulting inference would be that health education interventions that include medical professionals may be expected to reduce mortality rates by a rate of 30 neonatal deaths per 1,000 live births in comparison to programs without medical professional involvement. The level of confidence in this assertion is $P>0.95$.

\section{Discussion}

It may appear obvious that treatments involving medical professionals might be expected to be more effective in the reduction of neonatal mortality than those without medical professionals. However, this practical point with respect to health education in developing countries has had no empirical support prior to the present study. This study provides the first substantial evidence that the outcomes of such health education interventions are significantly enhanced by the involvement of medical professionals and, therefore, should be consequential for future policy guidelines and interventions. Further, the magnitude of the reported effect size, that is, a reduction of neonatal mortality rates of approximately 30 per 1,000 live births, should be difficult to put aside. Of course, most of the 14 studies reviewed in this paper have recommended scaling-up the existing interventions on the basis of success of the interventions in the reduction of neonatal mortality, yet there are few instances in which comparative analyses were made directly of alternative forms of health education programs in developing countries.

'One size fits all' approaches are very common in the impact evaluation literature for developing countries. That is, if an intervention was successful in one setting, it is recommended for other settings, as well, irrespective of cultural and contextual differences. It is recommended here to carefully tailor trials incorporating evidence-based practices with local needs, the particular capacity of health system, and specific cultural contexts. Very few studies, for example, Haws et al. [19] have appreciated this approach. Among reviewed studies, one of the greatest reductions in neonatal mortality was witnessed in interventions that were carefully tailored in their design and implementation to local needs and health system capacity. The examples of such studies are Kumar et al. [4] and Bang et al. [15] wherein the net mortality rate reductions from interventions were -53 and -43 respectively.

In addition, the interventions in which male members of the community, in addition to female, were included in the intervention appeared to be more effective and successful than those only directed 
toward pregnant women. For instance, the Midhet and Becker [14] study was comprised of two experimental groups: one, where only pregnant mothers were educated, and the second where husbands of pregnant women also were included. Results suggested that there was a greater reduction in neonatal mortality in the latter group. Since these interventions are designed for male-dominant societies, the inclusion of male members of a community will have a greater chance for making an intervention more culturally acceptable and, as a result, more consequential. Similarly, Kumar et al. [4] and Baqui et al. [10] recruited male community-based workers as part of interventions in India and Bangladesh, respectively. Both of these trials were reported to be very effective.

In this review, five out of the eight studies that included medical professionals were community-based interventions. There was only one community-based intervention in the six studies not involving medical professionals. The statistically significant differences between the two types of health education interventions reported in the present study may be due, in fact, to the combination of the inclusion of medical professionals and a larger community representation in the intervention. This possibility of an additional main effect or interaction cannot be excluded; further investigation is necessary but is beyond the evidentiary limitations of the present study. The primary positive effect does appear to result from the involvement of medical professionals in health education interventions in developing countries.

Although public health and medical journals have specified standard methods and protocols, a number of inconsistencies in reporting evaluation results were found in completing the present study. For example, some researchers stated that pre-test data were collected as part of the evaluation effort, but these baseline measurements were not included in the published article. Due to such incomplete reporting, DID statistics could not be calculated in at least ten instances. An additional four studies that might have been relevant to the present review were found to have been undertaken without a control group. As part of reporting requirements, researchers also should describe their evaluation study designs in quite specific detail. This will aid both practitioners and researchers in assessing the value of their findings. This point also has been emphasized in other systematic reviews such as Schiffman et al. [3] and Haws et al. [19]. Finally, an effort should be made to achieve greater standardization of measures in evaluation studies of specific program or policy interventions, as well. In the present review, 14 potentially relevant studies of health education programs that were directed toward pregnant women in developing countries - even studies with necessary baseline data and control groups - failed to collect and/or report neonatal mortality rates. Greater commitment to standard evaluation methods and protocols will increase the opportunities for improved learning from social experiments.

\section{References}

[1] WHO. Children: Reducing Morlality [http://www.who.int/mediacentre/factsheets/fs178/en/].

[2] Carlo, W. A., Goudar, S. S., Jehan, I., Chomba, E., Tshefu, A., Garces, A., Sailajanandan, P., Althabe, F., McClure, E. M., Derman, R. J., Goldenberg, R. L., Bose, C., Krebs, N. F., Panigrahi, P., Buekens, P., Chakraborty, H., Hartwell, T. D., and Wright, L. L. 2010. "Newborn-care Training and Perinatal Mortality in Developing Countries. New England Journal of Medicine 362: 614-23.

[3] Schiffman, J., Darmstadt, G. L., Agarwal, S., and Baqui, A. H. 2010. "Community-based Intervention Packages for Improving Perinatal Health in Developing Countries: a Review of the Evidence." Seminars in Perinatology 34 : 462-76.

[4] Kumar, V., Mohanty, S., Kumar, A., Misra, R. P., Santosham, M., Awasthi, S., Baqui, A. H., Singh, P., Singh, V., Ahuja, R. C., Singh, J. V., Malik, G. K., Ahmed, S., Black, R. E., Bhandari, M., and Darmstadt, G. L. 2008. "Effect of Community-based Behaviour Change Management on Neonatal Mortality in Shivgarh, Uttar Pradesh, India: a Cluster-randomised Controlled Trial." The Lancet 372: 1151-62.

[5] Kumar, V., Kumar, A., Das, V., Srivastava, N. M., Baqui, A. H., Santosham, M., Darmstadt, G. L., and Saksham Study, G. 2012. "Community-driven Impact of a 
Newborn-focused Behavioral Intervention on Maternal Health in Shivgarh, India." International Journal of Gynaecology and Obstetrics 117: 48-55.

[6] Azad, K., Barnett, S., Banerjee, B., Shaha, S., Khan, K., Rego, A. R., Barua, S., Flatman, D., Pagel, C., Prost, A., Ellis, M., and Costello, A. 2010. "Effect of Scaling up Women's Groups on Birth Outcomes in Three Rural Districts in Bangladesh: a Cluster-randomised Controlled Trial." The Lancet 375: 1193-202.

[7] Tripathy, P., Nair, N., Barnett, S., Mahapatra, R., Borghi, J., Rath, S., Rath, S., Gope, R., Mahto, D., Sinha, R., Lakshminarayana, R., Patel, V., Pagel, C., Prost, A., and Costello, A. 2010. "Effect of a Participatory Intervention with Women's Groups on Birth Outcomes and Maternal Depression in Jharkhand and Orissa, India: a Cluster-randomised Controlled Trial." The Lancet 375: 1182-92.

[8] Manandhar, D. S., Osrin, D., Shrestha, B. P., Mesko, N., Morrison, J., Tumbahangphe, K. M., Tamang, S., Thapa, S., Shrestha, D., Thapa, B., Shrestha, J. R., Wade, A., Borghi, J., Standing, H., Manandhar, M., and de L Costello, A. M. 2004. "Effect of a Participatory Intervention with Women's Groups on Birth Outcomes in Nepal: Cluster-randomised Controlled Trial." The Lancet 364: 970-9.

[9] Greenwood, A. M., Bradley, A. K., Byass, P., Greenwood, B. M., Snow, R. W., Bennett, S., and Hatib-N'Jie, A. B. 1990. "Evaluation of a Primary Health Care Programme in the Gambia. I. the Impact of Trained Traditional Birth Attendants on the Outcome of Pregnancy." The Journal of Tropical Medicine and Hygiene 93: 58-66.

[10] Baqui, A. H., El-Arifeen, S., Darmstadt, G. L., Ahmed, S., Williams, E. K., Seraji, H. R., Mannan, I., Rahman, S. M., Shah, R., Saha, S. K., Syed, U., Winch, P. J., Lefevre, A., Santosham, M., and Black, R. E. 2008. "Effect of Community-based Newborn-care Intervention Package Implemented through Two Service-delivery Strategies in Sylhet District, Bangladesh: a Cluster-randomised Controlled Trial." The Lancet 371: 1936-44.

[11] Kirkwood, B. R., Manu, A., ten Asbroek, A. H. A., Soremekun, S., Weobong, B., Gyan, T., Danso, S., Amenga-Etego, S., Tawiah-Agyemang, C., Owusu-Agyei, S., and Hill, Z. 2013. "Effect of the Newhints Home-visits
Intervention on Neonatal Mortality Rate and Care Practices in Ghana: a Cluster Randomised Controlled Trial." The Lancet 381: 2184-92.

[12] Bhutta, Z. A., Memon, Z. A., Soofi, S., Salat, M. S., Cousens, S., and Martines, J. 2008. "Implementing Community-based Perinatal Care: Results from a Pilot Study in Rural Pakistan." Bulletin of the World Health Organization 86: 452-9.

[13] Bang, A. T., Bang, R. A., Baitule, S. B., Reddy, M. H., and Deshmukh, M. D. 1999. "Effect of Home-based Neonatal Care and Management of Sepsis on Neonatal Mortality: Field Trial in Rural India." The Lancet 354: 1955-61.

[14] Midhet, F., and Becker, S. 2010. "Impact of Community-based Interventions on Maternal and Neonatal Health Indicators: Results from a Community Randomized Trial in Rural Balochistan, Pakistan." Reproductive Health 7: 1-10.

[15] Bang, A. T., Reddy, H. M., Deshmukh, M. D., Baitule, S. B., and Bang, R. A. 2005. "Neonatal and Infant Mortality in the Ten Years (1993 to 2003) of the Gadchiroli Field Trial: Effect of Home-based Neonatal Care." Journal of Perinatology 25: 92-107.

[16] Bhutta, Z. A., Soofi, S., Cousens, S., Mohammad, S., Memon, Z. A., Ali, I., Feroze, A., Raza, F., Khan, A., Wall, S., and Martines, J. 2011. "Improvement of Perinatal and Newborn Care in Rural Pakistan through Community-based Strategies: a Cluster-randomised Effectiveness Trial." Lancet 377: 403-12.

[17] Persson, L. Å., Nga, N. T., Målqvist, M., Thi Phuong Hoa, D., Eriksson, L., Wallin, L., Selling, K., Huy, T. Q., Duc, D. M., Tiep, T. V., Thi Thu Thuy, V., and Ewald, U. 2013. "Effect of Facilitation of Local Maternal-and-newborn Stakeholder Groups on Neonatal Mortality: Cluster-randomized Controlled Trial." PLoS Medicine 10: $1-11$.

[18] Jokhio, A. H., Winter, H. R., and Cheng, K. K. 2005. “An Intervention Involving Traditional Birth Attendants and Perinatal and Maternal Mortality in Pakistan." New England Journal of Medicine 352: 2091-9.

[19] Haws, R. A., Thomas, A. L., Bhutta, Z. A., and Darmstadt, G. L. 2007. "Impact of Packaged Interventions on Neonatal Health: a Review of the Evidence." Health Policy and Planning 22: 193-215. 